\title{
Screening of a highly inhibitor-tolerant bacterial strain for 2,3-BDO and organic acid production from non-detoxified corncob acid hydrolysate
}

\author{
Jing Wu' ${ }^{1}$ Yu-Jie Zhou ${ }^{1}$, Wen Zhang ${ }^{1}$, Ke-Ke Cheng ${ }^{2}$, Hong-Juan Liu ${ }^{1}$ and Jian-An Zhang ${ }^{1 *}$
}

\begin{abstract}
Fermentation of chemicals from lignocellulose hydrolysate is an effective way to alleviate environmental and energy problems. However, fermentation inhibitors in hydrolysate and weak inhibitor tolerance of microorganisms limit its development. In this study, atmospheric and room temperature plasma mutation technology was utilized to generate mutant strains of Enterobacter cloacae and screen for mutants with high inhibitor tolerance to acid hydrolysate of corncobs. A highly inhibitor-tolerant strain, Enterobacter cloacae M22, was obtained after fermentation with nondetoxified hydrolysate, and this strain produced $24.32 \mathrm{~g} / \mathrm{L}$ 2,3-butanediol and $14.93 \mathrm{~g} / \mathrm{L}$ organic acids. Compared with that of the wild-type strain, inhibitor tolerance was enhanced twofold with M22, resulting in improvement of 2,3-butanediol and organic acid production by $114 \%$ and $90 \%$, respectively. This work presents an efficient method to screen for highly inhibitor-tolerant strains and evidence of a novel strain that can produce 2,3-butanediol and organic acids using non-detoxified acid hydrolysate of corncobs.
\end{abstract}

Keywords: 2,3-Butanediol, Organic acid, Atmospheric and room temperature plasma (ARTP), Enterobacter cloacae, Non-detoxified hydrolysate

\section{Introduction}

2,3-Butanediol (2,3-BDO) is a staple chemical material and liquid fuel that is used extensively in the medical, food, and aerospace industries. 2,3-BDO can be used to manufacture flavour agents, edible spices, and solvents (Garg and Jain 1995; Tran and Chambers 1987; Zeng et al. 2016). The traditional chemical method used tetracarbonic hydrocarbons produced by petroleum pyrolysis as raw material and then obtained 2,3-butanediol by hydrolysis at high temperature and pressure. Dependence on petroleum resources and high production costs have limited the development of chemical method. Biological fermentation is not dependent on oil resources and therefore is considered a green route for 2,3-BDO

\footnotetext{
*Correspondence: zhangja@tsinghua.edu.cn

${ }^{1}$ Institute of Nuclear and New Energy Technology, Tsinghua University, Beijing 100084, China

Full list of author information is available at the end of the article
}

production, with carbohydrates converted to 2,3-BDO by microorganisms under mild conditions. Fermentation is accompanied by the formation of organic acids such as formic acid, acetic acid, and succinic acid, which also have many applications. In recent years, succinic acid has been extensively used in the synthesis of biodegradable polymers such as polybutylene succinate (PBS) and polyamide (Debuissy et al. 2017; Jiang et al. 2014).

The feedstock for 2,3-BDO and organic acid fermentation has been a focus of study worldwide. Typical 2,3-BDO fermentation used sugars such as glucose and xylose as substrates. Because of the high cost of sugars, some cheap feedstock such as starch, molasses, glycerol, and lignocellulosic materials have been utilized as substrates for 2,3-BDO fermentation (Bialkowska and Aneta 2016). Lignocellulosic materials are considered the most plentiful feedstock and an alternative for 2,3-BDO and organic acid production. The hemicellulose fraction accounts for $20-35 \%$ of lignocellulose materials, and 
hemicellulose is prone to being hydrolysed into monosaccharides with diluted acid pretreatment. However, the formation of by-products (e.g. formic acid, acetic acid, furfural, and 5-hydroxymethyl furfural) always accompanies dilute acid pretreatment of lignocellulose, which inhibits microbial growth and fermentation (Lloyd and Wyman 2005). Therefore, these inhibitors need to be removed when using dilute acid hydrolysate of lignocellulose as a substrate for 2,3-BDO fermentation. Many processes such as activated carbon adsorption, calcium neutralization, and organic solvent extraction have been applied to detoxification of the dilute acid hydrolysate of lignocellulose (Cheng et al. 2010; Jiang et al. 2012). However, the process of detoxification often leads to the loss of sugar, which reduces production yield. Another disadvantage of this process is the consumption of additional reagents that cannot be recycled.

The high raw material and operating costs of hydrolysate detoxification make fermentation uneconomical. Thus, using non-detoxified acid hydrolysate as a raw material for fermentation with inhibitor-tolerant strains seems attractive (Schirmer-Michel et al. 2009; Varga et al. 2004). Most wild-type microbes have low inhibitor tolerance. Mutation breeding methods are effective in improving strain characteristics. Many physical and chemical mutation methods involving ultraviolet radiation, X-ray, sodium azide, and diethyl sulphate have been reported in the literature (Bhagwat and Duncan 1998; Wang et al. 2007). However, traditional mutation methods are detrimental to health and have low mutation efficiency.

Atmospheric and room temperature plasma (ARTP) mutation is a novel technique that can be applied to the breeding of bacteria, fungi, yeast, actinomycetes, and microalgae (Zhang et al. 2014a), is easy and safe to perform, and has high mutation efficiency. Wang et al. used ARTP to mutate Streptomyces avermitilis and obtained a mutant with a higher abamectin yield (Wang et al. 2010). ARTP mutation was also applied to the breeding of Crypthecodinium cohnii for extracellular polysaccharide production (Liu et al. 2015). Cao et al. used the oleaginous microalgae Chlorella pyrenoidosa as the parent strain and, by ARTP, obtained a mutant with high lipid productivity. The dry weight and lipid productivity of the mutant strain were increased by $22.07 \%$ and $16.85 \%$, respectively (Cao et al. 2017). These results confirm that ARTP is an efficient mutagenesis tool for microbial breeding.

Many microorganisms such as Enterobacter, Klebsiella, Bacillus, Aeromonas, Pseudomonas, Serratia have been employed for 2,3-BDO production (Garg and Jain 1995; Bialkowska 2016). Enterobacter cloacae is considered to be one of the most promising strain for industrial application because of its stable performance under a wide range of environmental conditions and prominent tolerance to inhibitors. In addition, Enterobacter cloacae can use an extensive range of substrates to produce 2,3-BDO. The ability of Enterobacter cloacae to produce 2,3-BDO and succinic acid have been investigated by our group. Enterobacter cloacae can produce $77.1 \mathrm{~g} / \mathrm{L} 2,3-\mathrm{BDO}$ and $28.1 \mathrm{~g} / \mathrm{L}$ succinic acid from glucose. When using xylose as substrate, a maximum of $40.67 \mathrm{~g} / \mathrm{L} 2,3-\mathrm{BDO}$ and $21.79 \mathrm{~g} / \mathrm{L}$ succinic acid were obtained (Cheng et al. 2013; Wu et al. 2018). So, Enterobacter cloacae was used as the original strain in this study. Enterobacter cloacae cannot grow at the original $\mathrm{pH}$ of hydrolysate which is about 2 . Appropriate $\mathrm{pH}$ of cell growth and 2,3-BDO formation is 6.5. So the tolerance of Enterobacter cloacae to hydrolysate in this study was conducted at $\mathrm{pH}$ 6.5.

In this study, the ARTP mutation technique was used to create a library of Enterobacter cloacae mutants to screen for strains with high tolerance to inhibitors in corncob acid hydrolysate. The mutant strains were then used to produce 2,3-BDO and organic acids with non-detoxified corncob acid hydrolysate as the substrate. The selected mutant strain may be applied to biological detoxification of dilute acid hydrolysate of lignocellulose in other fermentation processes.

\section{Materials and methods \\ Strain and media}

The original strain used in this study was E. cloacae CICC 10011, which was purchased from the China Center of Industrial Culture Collection (CICC). The E. cloacae M22 obtained in this study has been deposited in China General Microbiological Culture Collection Center (CGMCC) and the preservation number is CGMCC NO. 17265.

The seed medium consisted of $30 \mathrm{~g} / \mathrm{L}$ xylose, $2 \mathrm{~g} / \mathrm{L}$ $\left(\mathrm{NH}_{4}\right)_{2} \mathrm{SO}_{4}, 4.4 \mathrm{~g} / \mathrm{L} \mathrm{K}_{2} \mathrm{HPO}_{4}, 1.3 \mathrm{~g} / \mathrm{L} \mathrm{KH}_{2} \mathrm{PO}_{4}, 1 \mathrm{~g} / \mathrm{L}$ yeast extract, $0.2 \mathrm{~g} / \mathrm{L} \mathrm{MgSO}{ }_{4} \cdot 7 \mathrm{H}_{2} \mathrm{O}, 1 \mathrm{~mL} / \mathrm{L}$ trace element solution, and $2 \mathrm{~mL} / \mathrm{L}$ Fe solution. The trace element solution contained $70 \mathrm{mg} / \mathrm{L} \mathrm{ZnCl} 2,0.1 \mathrm{~g} / \mathrm{L} \mathrm{MnCl}_{2} \cdot 4 \mathrm{H}_{2} \mathrm{O}, 60 \mathrm{mg} / \mathrm{L}$ $\mathrm{H}_{3} \mathrm{BO}_{3}, 0.2 \mathrm{~g} / \mathrm{L} \quad \mathrm{CoCl}_{2} \cdot 2 \mathrm{H}_{2} \mathrm{O}, 20 \mathrm{mg} / \mathrm{L} \quad \mathrm{CuCl}_{2} \cdot 2 \mathrm{H}_{2} \mathrm{O}$, $25 \mathrm{mg} / \mathrm{L} \mathrm{NiCl}_{2} \cdot 6 \mathrm{H}_{2} \mathrm{O}, 35 \mathrm{mg} / \mathrm{L} \mathrm{Na}_{2} \mathrm{MoO}_{4} \cdot 2 \mathrm{H}_{2} \mathrm{O}, 0.9 \mathrm{~mL} / \mathrm{L}$ $\mathrm{HCl}$, and Fe solution containing $5 \mathrm{~g} / \mathrm{L} \mathrm{FeSO}_{4} \cdot 7 \mathrm{H}_{2} \mathrm{O}$, and $4 \mathrm{~mL} / \mathrm{L} \mathrm{HCl}$. The $\mathrm{pH}$ of seed medium was 6.5 .

Acid hydrolysate of corncobs was diluted to various concentrations and used as fermentation medium containing $1.5 \mathrm{~g} / \mathrm{L}$ yeast extract.

\section{Corncob pretreatment}

The corncobs used as raw material for hydrolysis of dilute acids was obtained from Shandong province in China. The particle size of the corncobs was 20-40 mesh, and the main components of corncob are $2.67 \pm 0.04 \%$ 
benzene-ethanol extractives, $40.46 \pm 0.45 \%$ cellulose, $32.87 \pm 0.48 \%$ hemicellulose, $17.12 \pm 0.34 \%$ lignin.

Corncob particles were pre-treated with a mixed acid solution ( $1.5 \%$ sulfuric acid $+0.5 \%$ phosphoric acid), loaded into 500-mL flasks with a loading capacity of $30 \mathrm{~g}$ and $90 \mathrm{~g}$, respectively, and then heated to $130{ }^{\circ} \mathrm{C}$ for $1 \mathrm{~h}$ in an autoclave. The hydrolysate and solid residues were separated by filtration, and the filter cake was washed with $60 \mathrm{~mL}$ distilled water to increase the amount of sugars collected. The $\mathrm{pH}$ of the hydrolysate was adjusted to 5.5 with $\mathrm{NaOH}$ and 6.5 with ammonia.

\section{Tolerance of Enterobacter cloacae wild-type strains to hydrolysate}

Seed culture and fermentation experiments were carried out in a 500-mL flask. The strains were inoculated into $50 \mathrm{~mL}$ seed culture medium, and the flasks were cultivated on a shaker at $30{ }^{\circ} \mathrm{C}$ and $150 \mathrm{rpm}$ for $14-16 \mathrm{~h}$. Then, the seeds were inoculated into fermentation medium containing $25 \%, 50 \%, 75 \%$, and $100 \%$ corncob acid hydrolysate at an inoculation rate of $10 \%$ and cultivated on a shaker at $35{ }^{\circ} \mathrm{C}$ and $150 \mathrm{rpm}$ for fermentation. $\mathrm{CaCO}_{3}$ $(5 \mathrm{~g} / \mathrm{L})$ was used as a $\mathrm{pH}$ buffer during fermentation.

\section{Atmospheric and room temperature plasma mutation of Enterobacter cloacae}

The ARTP mutation breeding system was supplied by Professor Xinhui Xing of Tsinghua University and consisted of a coaxial type plasma generator, gas supply control subsystem, radiofrequency power supply, and sample plate made of stainless steel (Zhang et al. 2014b). The experimental process is shown in Fig. 1. Bacteria reached logarithmic growth $(O D \approx 1)$ before mutation. Ten microliters of the bacterial liquid was pipetted onto a sterilized sample plate and then treated for $0,60,120$, $180,240,300$, or $360 \mathrm{~s}$. The helium gas flow was 10 standard litres per minute, and plasma was induced at $120 \mathrm{~W}$.

After ARTP mutation, the cells on the stainless-steel plates were washed with fresh seed culture medium and then cultivated on a shaker at $30{ }^{\circ} \mathrm{C}$ and $150 \mathrm{rpm}$ for $1 \mathrm{~h}$. The activated bacteria were properly diluted, and $100 \mu \mathrm{L}$ bacterial suspension was coated on each plate with $75 \%$ diluted acid hydrolysate. The plates were placed in an incubator for $24 \mathrm{~h}$ at $30{ }^{\circ} \mathrm{C}$, and then the numbers of surviving clones were counted.

\section{Fermentation experiments}

The seed cells were inoculated into 500-mL flasks containing $100 \mathrm{~mL}$ fermentation medium at $10 \%(\mathrm{v} / \mathrm{v})$, then cultivated on a shaker at $35^{\circ} \mathrm{C}$ and $150 \mathrm{rpm}$ for fermentation. The $\mathrm{pH}$ was buffered with $5 \mathrm{~g} / \mathrm{L} \mathrm{GaCO}_{3}$. Each data point is the average of two replicates.

Fermentation was performed in a 1-L fermenter at $35{ }^{\circ} \mathrm{C}$ and $500 \mathrm{rpm}$ with ventilation of $0.2 \mathrm{vvm}$. The seed culture was transferred to $500 \mathrm{~mL}$ fermentation medium with an inoculation volume of $10 \%$, and the $\mathrm{pH}$ was maintained at 6.5 throughout fermentation by adding $4 \mathrm{~mol} / \mathrm{L}$ sodium hydroxide solution with an automatic controller.

\section{Analytical methods}

Cell concentration was monitored by measuring the optical density at $600 \mathrm{~nm}\left(\mathrm{OD}_{600}\right)$ with a UV spectrophotometer (JingHua 7600CRT, China). Then, components of the hydrolysate and fermentation products were analysed using a high-performance liquid chromatograph (HPLC, Shimadzu LC-20AT, Japan). The components were separated in an Aminex HPX-87H ion exclusion column (Bio Rad, USA) at $65{ }^{\circ} \mathrm{C}$, and $5 \mathrm{mM} \mathrm{H}_{2} \mathrm{SO}_{4}$ was used as the mobile phase with a flow rate of $0.8 \mathrm{~mL} / \mathrm{min}$. Concentrations of glucose, xylose, formic acid, acetic acid, succinic acid, and 2,3-BDO were determined using an RI detector. HMF and furfural were analysed with a UV detector at $210 \mathrm{~nm}$.

\section{Results}

\section{Corncob pretreatment}

Table 1 shows the main compounds of the dilute sulphuric acid hydrolysate from corncobs. The concentration of
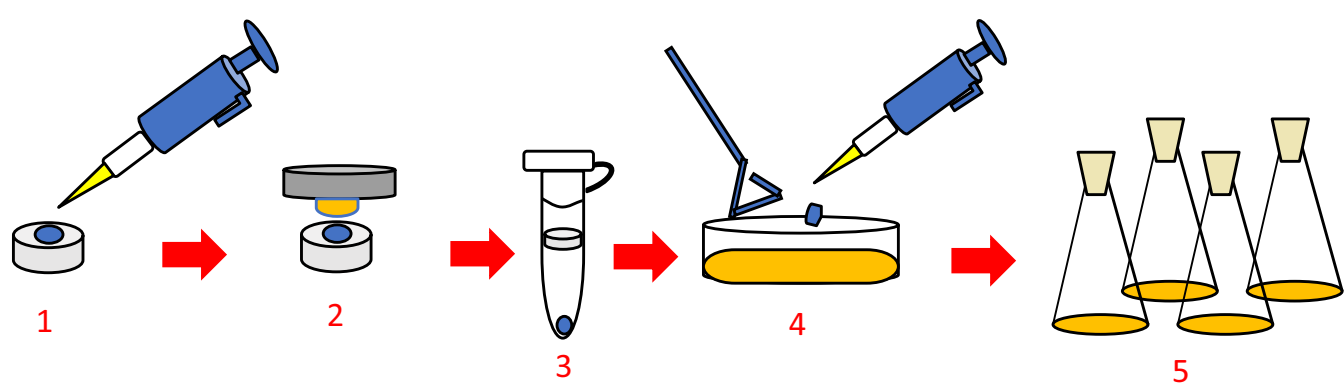

Fig. 1 ARTP mutation process (1. Sample loading. 2. Plasma treatment. 3. Bacterial elution. 4. Plate screening. 5. Fermentation screening) 
Table 1 Main components of dilute acid hydrolysate from corncobs

\begin{tabular}{lllllll}
\hline Glucose (g/L) & Xylose (g/L) & Arabinose (g/L) & Formic acid (g/L) & Acetic acid (g/L) & HMF (g/L) & Furfural (g/L) \\
\hline $6.66 \pm 0.13$ & $52.79 \pm 1.02$ & $8.12 \pm 0.22$ & $0.76 \pm 0.03$ & $7.26 \pm 0.31$ & $0.24 \pm 0.01$ & $0.89 \pm 0.10$ \\
\hline
\end{tabular}

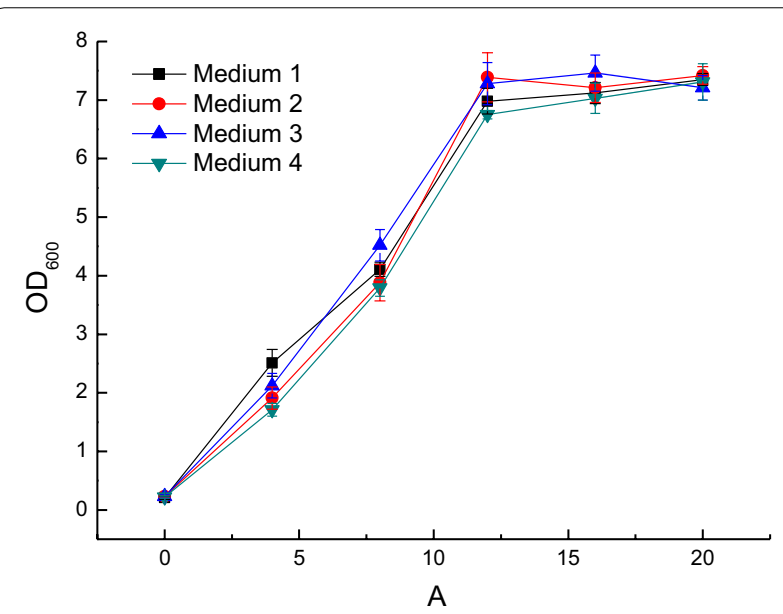

Fig. 2 Cell growth in different sugar concentrations (Medium 1: $1.5 \mathrm{~g} / \mathrm{L}$ glucose, $12 \mathrm{~g} / \mathrm{L}$ xylose, $2 \mathrm{~g} / \mathrm{L}$ arabinose. Medium 2: $3 \mathrm{~g} / \mathrm{L}$ glucose, $24 \mathrm{~g} / \mathrm{L}$ xylose, $3.5 \mathrm{~g} / \mathrm{L}$ arabinose. Medium 3: $4.5 \mathrm{~g} / \mathrm{L}$ glucose, $36 \mathrm{~g} / \mathrm{L}$ xylose, $5.5 \mathrm{~g} / \mathrm{L}$ arabinose. Medium 4: $6 \mathrm{~g} / \mathrm{L}$ glucose, $48 \mathrm{~g} / \mathrm{L}$ xylose, $7 \mathrm{~g} / \mathrm{L}$ arabinose.)

total sugars was $67.57 \mathrm{~g} / \mathrm{L}$, and the mass ratio of glucose, xylose, and arabinose was 1:8:1.2. Xylose was the main carbon source and was attributable to the degradation of hemicellulose during dilute acid pretreatment. The amount of acetic acid was greater than that of the other inhibitors.

\section{Tolerance of Enterobacter cloacae wild-type strains to hydrolysate}

Culture medium containing $25 \%, 50 \%, 75 \%$, or $100 \%$ acid hydrolysate from corncobs was used as a substrate to investigate the tolerance of E. cloacae to hydrolysate. In addition, culture medium containing same sugar concentration as hydrolysate were used to study the effects of different sugar concentrations on cell growth. The results showed that sugar concentration had no significant effect on cell growth (Fig. 2), which proved that the sugars in hydrolysate have no inhibitory effect on cell growth within the range of concentration investigated. Tables 2 and 3 show the concentration of each component before and after fermentation, respectively. Use of $25 \%$ hydrolysate resulted in no obvious inhibition of $E$. cloacae. The sugar consumption achieved $99.01 \%$ at $18 \mathrm{~h}$ with a sugar consumption rate of $0.83 \mathrm{~g} / \mathrm{L} / \mathrm{h}$. The final concentration of 2,3-BDO was $6.27 \mathrm{~g} / \mathrm{L}$. The 2,3-BDO productivity and yield were $0.35 \mathrm{~g} / \mathrm{L} / \mathrm{h}$ and $0.42 \mathrm{~g} / \mathrm{g}$ sugar, respectively. The initial concentrations of formic acid and acetic acid were $0.17 \mathrm{~g} / \mathrm{L}$ and $1.68 \mathrm{~g} / \mathrm{L}$, respectively, in $25 \%$ hydrolysate. The production of organic acids during fermentation were $0.82 \mathrm{~g} / \mathrm{L}$ succinic acid, $0.04 \mathrm{~g} / \mathrm{L}$ formic

Table 2 The concentration of each component before fermentation

\begin{tabular}{|c|c|c|c|c|c|c|c|}
\hline $\begin{array}{l}\text { Hydrolysate } \\
\text { concentration } \\
(\%)\end{array}$ & Glucose (g/L) & Xylose (g/L) & Arabinose (g/L) & Formic acid (g/L) & Acetic acid (g/L) & HMF (g/L) & Furfural $(g / L)$ \\
\hline 25 & $1.11 \pm 0.05$ & $12.17 \pm 0.17$ & $1.82 \pm 0.03$ & $0.17 \pm 0.01$ & $1.68 \pm 0.15$ & $0.05 \pm 0.01$ & $0.21 \pm 0.02$ \\
\hline 50 & $2.98 \pm 0.10$ & $25.86 \pm 0.88$ & $3.59 \pm 0.11$ & $0.34 \pm 0.01$ & $3.22 \pm 0.12$ & $0.10 \pm 0.01$ & $0.39 \pm 0.02$ \\
\hline 75 & $4.56 \pm 0.12$ & $35.77 \pm 1.03$ & $5.53 \pm 0.12$ & $0.52 \pm 0.03$ & $5.03 \pm 0.16$ & $0.17 \pm 0.02$ & $0.61 \pm 0.01$ \\
\hline 100 & $5.72 \pm 0.09$ & $47.63 \pm 1.15$ & $7.09 \pm 0.20$ & $0.68 \pm 0.02$ & $6.41 \pm 0.15$ & $0.21 \pm 0.02$ & $0.79 \pm 0.03$ \\
\hline
\end{tabular}

Table 3 Results of fermentation with different concentrations of hydrolysate

\begin{tabular}{|c|c|c|c|c|c|c|c|c|}
\hline $\begin{array}{l}\text { Hydrolysate } \\
\text { concentration } \\
(\%)\end{array}$ & $\begin{array}{l}\text { Sugar } \\
\text { utilization (\%) }\end{array}$ & $\begin{array}{l}\text { Succinic acid } \\
(g / L)\end{array}$ & $\begin{array}{l}\text { Formic acid } \\
\text { (g/L) }\end{array}$ & $\begin{array}{l}\text { Acetic acid } \\
\text { (g/L) }\end{array}$ & Acetoin (g/L) & 2,3-BDO (g/L) & Ethanol (g/L) & $O D_{600}$ \\
\hline 25 & $99.01 \pm 0.25$ & $0.82 \pm 0.08$ & $0.21 \pm 0.02$ & $4.73 \pm 0.17$ & $0.89 \pm 0.10$ & $6.27 \pm 0.15$ & $0.22 \pm 0.04$ & $6.78 \pm 0.11$ \\
\hline 50 & $85.12 \pm 0.62$ & $1.43 \pm 0.12$ & $0.36 \pm 0.04$ & $8.69 \pm 0.21$ & $1.02 \pm 0.08$ & $10.84 \pm 0.26$ & $0.37 \pm 0.07$ & $6.66 \pm 0.20$ \\
\hline 75 & $2.03 \pm 0.11$ & - & $0.49 \pm 0.01$ & $5.51 \pm 0.13$ & - & - & & $0.53 \pm 0.06$ \\
\hline 100 & - & - & $0.66 \pm 0.02$ & $6.34 \pm 0.32$ & - & - & & - \\
\hline
\end{tabular}


acid and $3.05 \mathrm{~g} / \mathrm{L}$ acetic acid. When $50 \%$ hydrolysate was used as the substrate, the utilization of sugar decreased to $85 \%$ and the fermentation time was extended to $40 \mathrm{~h}$ due to relatively high inhibition. The sugar consumption rate was only $0.69 \mathrm{~g} / \mathrm{L} / \mathrm{h}$. The production of $2,3-\mathrm{BDO}$ increased to $10.84 \mathrm{~g} / \mathrm{L}$ but the the 2,3-BDO productivity and yield decreased to $0.27 \mathrm{~g} / \mathrm{L} / \mathrm{h}$ and $0.39 \mathrm{~g} / \mathrm{g}$ sugar, respectively. The values of organic acids in Table 3 were the final concentrations in the fermentation broth. The actual amount of organic acids formed during fermentation were $1.43 \mathrm{~g} / \mathrm{L}$ succinic acid, $0.02 \mathrm{~g} / \mathrm{L}$ formic acid and $5.47 \mathrm{~g} / \mathrm{L}$ acetic acid. Use of $75 \%$ hydrolysate almost completely inhibited the growth of E. cloacae. Only $2 \%$ of sugar was utilized, and cell growth only reached 0.53 . Therefore, $75 \%$ hydrolysate was used as the preliminary screening medium.

\section{Mutation and primary screening of the mutants}

The mutants were screened by culture and fermentation, and, in general, a lethality rate of $90-99 \%$ was considered appropriate. In this study, an efficient and rapid screening method of directional screening on plates containing $75 \%$ diluted acid hydrolysate was developed. The number of colonies on plates after different treatment times is shown in Fig. 3. E. cloacae was subjected to ARTP mutation for times ranging from 60 to $360 \mathrm{~s}$. Untreated $E$. cloacae, used as a control, resulted in 30 surviving clones. The corresponding numbers of surviving colonies were $0,4,193,18,10$, and 1 when the treatment times were $60,120,180,240,300$, and $360 \mathrm{~s}$, respectively. When the treatment time was less than $180 \mathrm{~s}$, the positive mutation rate was low and few colonies grow on the plates due to the presence of inhibitors. The positive mutation rate reached the maximum at $180 \mathrm{~s}$ of treatment time and the number of colonies on the plate increased sharply. When the treatment time was greater than $180 \mathrm{~s}$, most of the cells died because of the high lethal rate, and few colonies grew on the plate. Therefore, an ARTP mutation time of $180 \mathrm{~s}$ was considered optimal. One hundred and ninetythree colonies were selected from the solid medium and inoculated into test tubes containing $5 \mathrm{~mL}$ seed culture medium for $14 \mathrm{~h}$ incubation at $30{ }^{\circ} \mathrm{C}$. Then, the bacterial fluid was streak-inoculated onto plates containing $100 \%$ hydrolysate medium. There were only 23 strains that grew on the $100 \%$ hydrolysate solid medium.

Treatment time is a key parameter in ARTP mutation. The optimum treatment time is determined by the original strain and screening conditions. For example, $60 \mathrm{~s}$ of treatment time is suitable for the mutation of Spirulina platensis to improve carbohydrate productivity (Fang et al. 2013), whereas Hua used LB agar plates containing $9.0 \% \mathrm{NaCl}$ to screen for mutants of $E$. cloacae. At a treatment time of $2 \mathrm{~min}$, $90 \%$ cell lethality was observed (Hua et al. 2010). As for the oleaginous microalgae Chlorella pyrenoidosa, when the treatment time was $40 \mathrm{~s}, 50 \mathrm{~s}$, or $60 \mathrm{~s}$, mortality rates reached $95.69 \%, 98.05 \%$, and $99.88 \%$, respectively (Cao et al. 2017).

\section{Fermentation of 2,3-butanediol and organic acids by mutants with hydrolysate}

The fermentation performance of 23 mutants was investigated with $100 \%$ hydrolysate as the substrate. Figure 4 shows the cell growth of mutants at $24 \mathrm{~h}$. Only 10 mutants were able to grow steadily $\left(\mathrm{OD}_{600}>6.0\right)$ and produce 2,3$\mathrm{BDO}$ and organic acids. Another 13 mutants grew to varying degrees, but there were no fermentation products. Table 4 shows the fermentation results for the mutants. The sugar utilization of 10 mutants was higher than $80 \%$, and their ability to ferment $2,3-\mathrm{BDO}$ and organic acids with non-detoxified hydrolysate was much greater

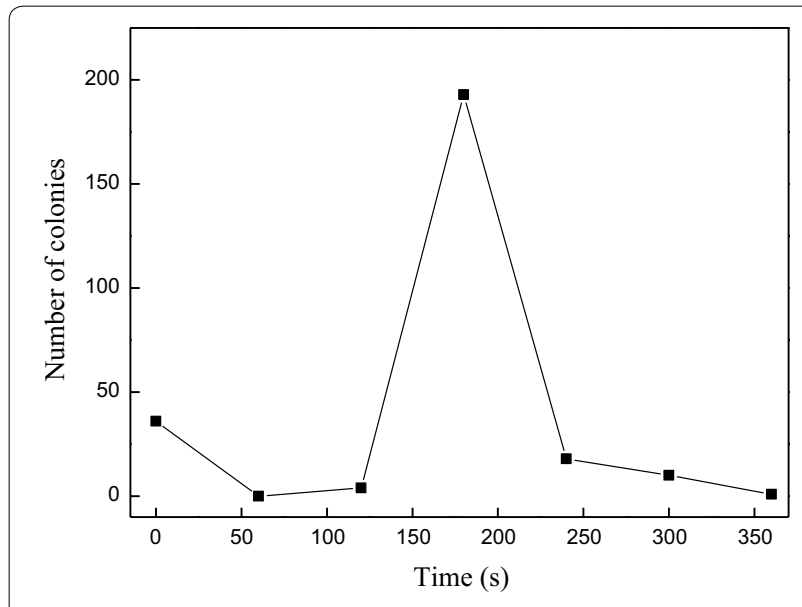

Fig. 3 Number of colonies on plates under different mutation times

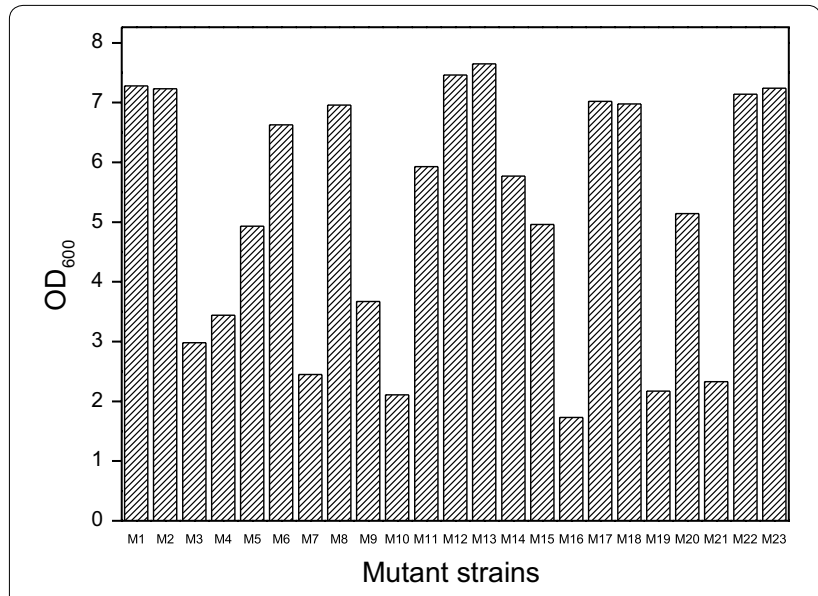

Fig. 4 Cell growth of 23 mutants in 100\% hydrolysate 
than that of the wild-type strain. Good genetic stability is essential for a mutant to be optimal for fermentation. Therefore, the stable fermentation performance of the mutants with non-detoxified hydrolysate was verified. The mutants were cultivated in seed medium for five generations and then inoculated into non-detoxified hydrolysate for fermentation. The inhibitor tolerance of most mutants decreased, with only mutant M22 maintaining greater fermentation ability (Table 5 ). The sugar utilization of M22 was $88.69 \%$, and the production of 2,3-BDO and organic acids was $24.32 \mathrm{~g} / \mathrm{L}$ and $14.93 \mathrm{~g} / \mathrm{L}$, respectively. Long-term stability of M22 is shown in Table 6. The 43 generations of M22 transmission still maintained good fermentation performance.

M22 was used for the co-production of 2,3-BDO and organic acids with non-detoxified hydrolysate in a 1-L fermenter. Sodium bicarbonate $(5 \mathrm{~g} / \mathrm{L})$ was added at fermentation times of 12 and $36 \mathrm{~h}$, respectively, to enhance the production of succinic acid. Previously, E. cloacae has been reported to show high co-production of 2,3-BDO

Table 4 Results of fermentation with non-detoxified hydrolysate

\begin{tabular}{|c|c|c|c|c|c|c|c|c|}
\hline Mutants & $\begin{array}{l}\text { Sugar utilization } \\
\text { (\%) }\end{array}$ & $\begin{array}{l}\text { Succinic acid } \\
(\mathrm{g} / \mathrm{L})\end{array}$ & Formic acid (g/L) & Acetic acid (g/L) & Acetoin (g/L) & 2,3-BDO (g/L) & Ethanol (g/L) & $\mathrm{OD}_{600}$ \\
\hline M1 & $87.04 \pm 1.51$ & $2.70 \pm 0.26$ & $1.52 \pm 0.10$ & $6.98 \pm 0.26$ & $1.04 \pm 0.12$ & $14.62 \pm 1.03$ & $1.71 \pm 0.21$ & $7.28 \pm 0.33$ \\
\hline M2 & $86.71 \pm 0.98$ & $2.49 \pm 0.17$ & $1.92 \pm 0.13$ & $6.73 \pm 0.30$ & $0.87 \pm 0.07$ & $16.48 \pm 1.15$ & $1.79 \pm 0.14$ & $7.23 \pm 0.21$ \\
\hline M6 & $84.88 \pm 1.22$ & $1.24 \pm 0.05$ & $1.05 \pm 0.08$ & $8.08 \pm 0.22$ & $3.18 \pm 0.23$ & $15.29 \pm 0.77$ & $1.02 \pm 0.10$ & $6.63 \pm 0.16$ \\
\hline M8 & $85.20 \pm 1.53$ & $1.48 \pm 0.22$ & $1.28 \pm 0.01$ & $7.01 \pm 0.29$ & $1.96 \pm 0.16$ & $14.60 \pm 0.53$ & $1.15 \pm 0.07$ & $6.69 \pm 0.20$ \\
\hline M12 & $85.67 \pm 2.01$ & $1.87 \pm 0.14$ & $0.72 \pm 0.06$ & $6.77 \pm 0.37$ & $1.98 \pm 0.09$ & $15.23 \pm 0.46$ & $0.87 \pm 0.11$ & $7.46 \pm 0.13$ \\
\hline M13 & $85.39 \pm 1.10$ & $1.73 \pm 0.20$ & $1.34 \pm 0.12$ & $6.65 \pm 0.18$ & $1.84 \pm 0.14$ & $14.74 \pm 0.82$ & $0.86 \pm 0.04$ & $7.65 \pm 0.17$ \\
\hline M17 & $87.67 \pm 2.57$ & $1.86 \pm 0.11$ & $1.27 \pm 0.08$ & $6.90 \pm 0.21$ & $1.71 \pm 0.21$ & $15.29 \pm 0.65$ & $1.21 \pm 0.10$ & $7.02 \pm 0.25$ \\
\hline M18 & $85.46 \pm 1.72$ & $1.69 \pm 0.14$ & $2.18 \pm 0.15$ & $6.76 \pm 0.13$ & $1.80 \pm 0.06$ & $14.85 \pm 0.19$ & $1.11 \pm 0.02$ & $6.98 \pm 0.19$ \\
\hline M22 & $85.98 \pm 1.69$ & $1.52 \pm 0.09$ & $1.15 \pm 0.08$ & $7.01 \pm 0.09$ & $2.21 \pm 0.10$ & $14.49 \pm 0.29$ & $0.88 \pm 0.04$ & $7.14 \pm 0.08$ \\
\hline M23 & $85.58 \pm 2.41$ & $1.70 \pm 0.12$ & $1.38 \pm 0.11$ & $6.77 \pm 0.26$ & $1.71 \pm 0.20$ & $14.90 \pm 0.40$ & $1.18 \pm 0.12$ & $7.24 \pm 0.20$ \\
\hline
\end{tabular}

Table 5 Fermentation stability of mutants with non-detoxified hydrolysate

\begin{tabular}{|c|c|c|c|c|c|c|c|c|}
\hline Mutants & $\begin{array}{l}\text { Sugar utilization } \\
(\%)\end{array}$ & $\begin{array}{l}\text { Succinic acid } \\
(\mathrm{g} / \mathrm{L})\end{array}$ & Formic acid (g/L) & Acetic acid (g/L) & Acetoin (g/L) & 2,3-BDO (g/L) & Ethanol (g/L) & $\mathrm{OD}_{600}$ \\
\hline$M 1$ & - & - & $0.72 \pm 0.06$ & $7.84 \pm 0.28$ & - & - & - & - \\
\hline M2 & $39.05 \pm 0.69$ & $0.79 \pm 0.04$ & $1.28 \pm 0.11$ & $6.19 \pm 0.19$ & $2.18 \pm 0.12$ & $14.01 \pm 0.64$ & $1.01 \pm 0.02$ & $7.33 \pm 0.20$ \\
\hline M6 & $12.17 \pm 0.33$ & - & $1.34 \pm 0.09$ & $7.70 \pm 0.37$ & $2.01 \pm 0.12$ & $7.10 \pm 0.35$ & - & $7.14 \pm 0.18$ \\
\hline M8 & - & - & $0.69 \pm 0.01$ & $7.69 \pm 0.24$ & - & - & - & - \\
\hline M12 & - & - & $0.68 \pm 0.03$ & $7.98 \pm 0.31$ & - & - & - & - \\
\hline M13 & $3.80 \pm 0.19$ & - & $0.69 \pm 0.01$ & $7.45 \pm 0.29$ & - & - & - & $5.96 \pm 0.08$ \\
\hline M17 & - & - & $0.70 \pm 0.02$ & $7.17 \pm 0.30$ & - & - & - & - \\
\hline M18 & - & - & $0.68 \pm 0.03$ & $7.56 \pm 0.11$ & - & - & - & - \\
\hline M22 & $88.69 \pm 1.09$ & $1.80 \pm 0.09$ & $2.18 \pm 0.11$ & $10.95 \pm 0.76$ & $2.72 \pm 0.07$ & $24.32 \pm 0.71$ & $1.27 \pm 0.02$ & $7.11 \pm 0.12$ \\
\hline M23 & $18.36 \pm 0.59$ & $0.46 \pm 0.06$ & $1.37 \pm 0.07$ & $8.01 \pm 0.15$ & $2.29 \pm 0.11$ & $9.53 \pm 0.22$ & - & $6.89 \pm 0.19$ \\
\hline
\end{tabular}

Table 6 Fermentation stability of E. aerogenes M22 with non-detoxified hydrolysate

\begin{tabular}{|c|c|c|c|c|c|c|c|c|}
\hline Generation & $\begin{array}{l}\text { Sugar } \\
\text { utilization (\%) }\end{array}$ & $\begin{array}{l}\text { Succinic acid } \\
\text { (g/L) }\end{array}$ & $\begin{array}{l}\text { Formic acid } \\
\text { (g/L) }\end{array}$ & Acetic acid (g/L) & Acetoin $(\mathrm{g} / \mathrm{L})$ & 2,3-BDO (g/L) & Ethanol (g/L) & $O_{600}$ \\
\hline 12 & $87.12 \pm 0.99$ & $1.69 \pm 0.11$ & $2.03 \pm 0.10$ & $9.92 \pm 0.53$ & $2.61 \pm 0.15$ & $23.59 \pm 0.82$ & $1.11 \pm 0.07$ & $7.23 \pm 0.12$ \\
\hline 23 & $88.63 \pm 1.04$ & $1.75 \pm 0.09$ & $2.41 \pm 0.17$ & $11.07 \pm 0.21$ & $3.03 \pm 0.12$ & $24.71 \pm 0.33$ & $1.44 \pm 0.04$ & $6.99 \pm 0.25$ \\
\hline $31^{\mathrm{a}}$ & $97.15 \pm 1.25$ & $1.44 \pm 0.10$ & $2.01 \pm 0.06$ & $8.97 \pm 0.18$ & $2.68 \pm 0.13$ & $19.99 \pm 0.61$ & $1.19 \pm 0.07$ & $7.14 \pm 0.13$ \\
\hline $40^{\mathrm{a}}$ & $96.71 \pm 0.78$ & $1.34 \pm 0.06$ & $1.93 \pm 0.09$ & $8.74 \pm 0.22$ & $2.61 \pm 0.11$ & $20.07 \pm 0.55$ & $1.02 \pm 0.06$ & $7.01 \pm 0.26$ \\
\hline 43 & $87.73 \pm 1.12$ & $1.78 \pm 0.20$ & $2.11 \pm 0.06$ & $10.33 \pm 0.19$ & $2.74 \pm 0.13$ & $23.87 \pm 0.57$ & $1.23 \pm 0.03$ & $7.12 \pm 0.22$ \\
\hline
\end{tabular}

a The substrate was $75 \%$ hydrolysate 
and succinic acid from sugar (Cheng et al. 2013; Wu et al. 2018), and addition of bicarbonate salts to the fermentation medium can increase the amount of dissolved $\mathrm{CO}_{2}$, which is an indispensable substrate for the formation of succinic acid. The final concentration of succinic acid reached $7.33 \mathrm{~g} / \mathrm{L}$ in this study. After fermentation, $1.02 \mathrm{~g} / \mathrm{L}$ formic acid and $4.68 \mathrm{~g} / \mathrm{L}$ acetic acid were produced. The final concentrations of 2,3-BDO and organic acids were $23.2 \mathrm{~g} / \mathrm{L}$ and $19.93 \mathrm{~g} / \mathrm{L}$, respectively, the yield of 2,3-BDO was $0.44 \mathrm{~g} / \mathrm{g}$ sugar. (Figure 5).

\section{Discussion}

The inhibition of fermentation inhibitors in acid hydrolysate on microorganisms limit the utilization of lignocellulose material. The mechanisms underlying inhibition of organic acids and furans have been reported. Undissociated acetic acid is the key factor for inhibition of other microorganisms (Cheng et al. 2005). Molecules of organic acids in a free state can freely shuttle through cell membranes, leading to acidification of the intracellular environment and inhibiting the synthesis of DNA and RNA (Parawira and Tekere 2011). In 2,3-BDO fermentation, a small amount of acetic acid has no obvious inhibitory effect; rather, it is beneficial (Wu et al. 2013a). However, the simultaneous presence of acetic acid and furfural strongly inhibits interactions (Wu et al. 2013b). Furan derivatives, mainly furfural and HMF, are dehydrated from pentose and hexose, respectively, in acidic environments. Their inhibitory effects on microorganisms are as follows: (i) they destroy the integrity of protoplasmic membranes and increase the permeability of cell membranes; (ii) they have direct inhibitory effects on various enzymes in the glycolysis pathway; (iii) they inhibit the synthesis or accelerate the degradation of $\operatorname{NAD}(\mathrm{P})$

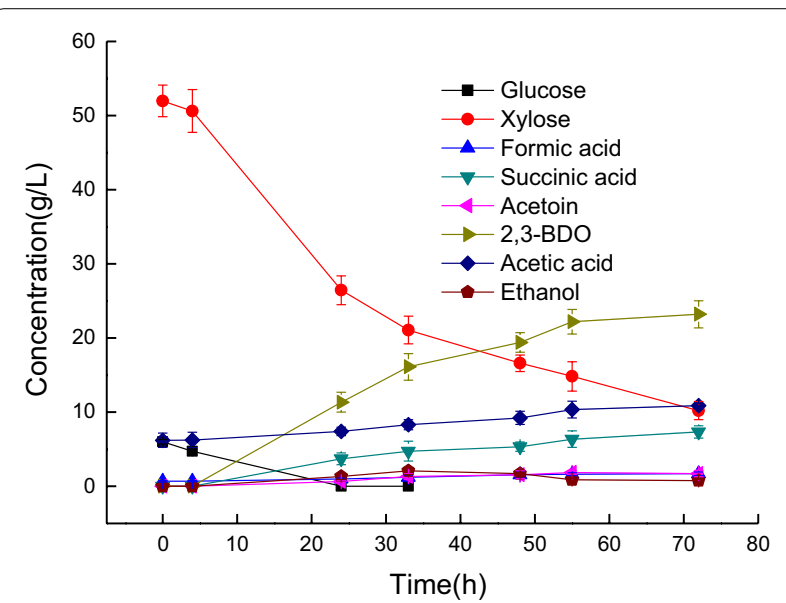

Fig. 5 Co-production of 2,3-BDO and organic acids by M22 with non-detoxified hydrolysate
$\mathrm{H}$ in cells; and (iv) dipole moments of large aldehyde groups result in a sharp rise in reactive oxygen in cells, which damages the cytoskeleton and inhibits cell growth (Allen et al. 2010; Feron et al. 1991; Liu et al. 2013; Miller et al. 2009). According to the literature, the furfural has higher negative effect of on biomass formation. The inhibitions of HMF and acetic acid were about $1 / 2$ and $1 / 10$, respectively, of that of furfural (Wu et al. 2013a). In this study, the furfural and HMF were converted to their less toxic alcohols, furfuryl alcohol and furan-2,5-diyldimethanol, respectively, during the fermentation. Phenolic compounds in hydrolysate are derived from lignin as it degrades. These compounds can destroy or decompose cytomembranes. In general, the smaller the substituents on aromatic rings, the greater the inhibition (Almeida 2010).

Fermentation of 2,3-BDO from non-detoxified biomass hydrolysate by Enterobacter has been reported previously (Table 7). Hazeena et al. used non-detoxified oil palm frond hydrolysate as the substrate for fermentation of 2,3-BDO by E. cloacae SG-1. The lag period of bacterial growth was longer than that of glucose because of inhibitors present in the hydrolysate, and the concentration of 2,3-BDO was 7.67 g/L (Hazeena et al. 2016). Joo et al. investigated the effects of inhibitory compounds on E. aerogenes. Three hydrolysates, yellow poplar, larix, and rice hull hydrolysates, were used as substrates to produce 2,3-BDO, and $14.27 \mathrm{~g} / \mathrm{L}, 12.44 \mathrm{~g} / \mathrm{L}$, and $10.24 \mathrm{~g} / \mathrm{L}$, respectively, were produced (Joo et al. 2016). E. aerogenes ATCC 29007 also has the ability to resist inhibitors. With a Miscanthus hydrolysate containing $34.62 \mathrm{~g} / \mathrm{L}$ of reducing sugar as a substrate, $11.00 \mathrm{~g} / \mathrm{L}$ of $2,3-\mathrm{BDO}$ was obtained (Lee et al. 2015).

In this study, ARTP mutation technology was used to generate mutants of E. cloacae to screen for a strain with high inhibitor tolerance to corncob acid hydrolysate. Fermentation performance and genetic stability

Table 7 Fermentation of 2,3-BDO from undetoxified biomass hydrolysate

\begin{tabular}{|c|c|c|c|}
\hline Raw material & Strain & 2,3-BDO (g/L) & Reference \\
\hline Oil palm frond & E. cloacae SG-1 & 7.67 & $\begin{array}{l}\text { Hazeena et al. } \\
(2016)\end{array}$ \\
\hline Yellow poplar & \multirow{3}{*}{$\begin{array}{l}\text { E. aerogenes KCTC } \\
2190\end{array}$} & 14.27 & \multirow[t]{3}{*}{ Joo et al. (2016) } \\
\hline Larix & & 12.44 & \\
\hline Rice hull & & 10.24 & \\
\hline Miscanthus & $\begin{array}{l}\text { E. aerogenes ATCC } \\
29007\end{array}$ & 11.00 & Lee et al. (2015) \\
\hline Corncob & $\begin{array}{l}\text { E. cloacae CICC } \\
10011\end{array}$ & 10.84 & This study \\
\hline Corncob & E. cloacae M22 & 23.20 & This study \\
\hline
\end{tabular}


with non-detoxified hydrolysate of one mutant, E. cloacae M22, was examined. Compared with that of the wildtype strain, inhibitor tolerance was enhanced twofold in M22. The wild-type strains can tolerate only $50 \%$ hydrolysate and produce $10.84 \mathrm{~g} / \mathrm{L} 2,3-\mathrm{BOD}$ and $6.92 \mathrm{~g} / \mathrm{L}$ organic acids. The mutant strain M4 can tolerate $100 \%$ hydrolysate and produce $23.2 \mathrm{~g} / \mathrm{L} 2,3-\mathrm{BOD}$ and $13.03 \mathrm{~g} / \mathrm{L}$ organic acids which increased by $114 \%$ and $88 \%$, respectively. E. cloacae M22 showed super inhibitor tolerance, and $23.2 \mathrm{~g} / \mathrm{L}$ 2,3-BDO was produced from non-detoxified corncob acid hydrolysate. This production yield was superior to that reported elsewhere (Hazeena et al. 2016; Joo et al. 2016; Lee et al. 2015).

\section{Authors' contributions}

JW carried out the writing and editing of manuscript. J-AZ carried out the review of manuscript and funding acquisition. Y-JZ and WZ carried out the sample detection. K-KC and $\mathrm{H}-\mathrm{JL}$ carried out the data analysis and data curation. All authors read and approved the final manuscript.

\section{Acknowledgements}

This work was supported by the National Key R\&D Program of China (No. 2016YFE0131300) and the NSFC-NRCT project (No. 51861145103). We appreciate Prof. Xinhui Xing and his group for their help in ARTP mutation.

\section{Ethics approval and consent to participate}

This article does not contain any studies with human participants performed by any of the authors.

\section{Competing interests}

The authors declare that they have no competing interests.

\section{Author details}

${ }^{1}$ Institute of Nuclear and New Energy Technology, Tsinghua University, Beijing 100084, China. ${ }^{2}$ School of Chemical Engineering and Energy Technology, Dongguan University of Technology, Dongguan 523808, China.

Received: 6 September 2019 Accepted: 11 September 2019 Published online: 24 September 2019

\section{References}

Allen SA, Clark W, Mccaffery JM, Cai Z, Lanctot A, Slininger PJ, Liu ZL, Gorsich SW (2010) Furfural induces reactive oxygen species accumulation and cellular damage in Saccharomyces cerevisiae. Biotechnol Biofuels 3(1):2

Almeida JRM (2010) Increased tolerance and conversion of inhibitors in lignocellulosic hydrolysates by Saccharomyces cerevisiae. J Chem Technol Biotechnol. 82(4):340-349

Bhagwat B, Duncan EJ (1998) Mutation breeding of banana cv Highgate (Musa spp., AAA Group) for tolerance to Fusarium oxysporum f. sp. cubense using chemical mutagens. Sci Horticult 73(1):11-22

Bialkowska AM (2016) Strategies for efficient and economical 2,3-butanediol production: new trends in this field. World J Microbiol Biotechnol 32:200

Cao S, Zhou X, Jin WB, Wang F, Tu RJ, Han SF, Chen HY, Chen C, Xie GJ, Ma F (2017) Improving of lipid productivity of the oleaginous microalgae Chlorella pyrenoidosa via atmospheric and room temperature plasma (ARTP). Bioresour Technol 244:1400-1406

Cheng KK, Liu HJ, Liu DH (2005) Multiple growth inhibition of Klebsiella pneumoniae in 1, 3-propanediol fermentation. Biotechnol Lett 27(1):19-22

Cheng KK, Liu Q, Zhang JA, Li JP, Xu JM, Wang GH (2010) Improved 2,3-butanediol production from corn cob acid hydrolysate by fed-batch fermentation using Klebsiella oxytoca. Process Biochem 45(4):613-616
Cheng KK, Wu J, Wang GY, Li WY, Feng J, Zhang JA (2013) Effects of pH and dissolved $\mathrm{CO}_{2}$ level on simultaneous production of 2,3-butanediol and succinic acid using Klebsiella pneumoniae. Bioresour Technol. 135:500-503

Debuissy T, Sangwan P, Pollet E, Averous L (2017) Study on the structure-properties relationship of biodegradable and biobased aliphatic copolyesters based on 1,3-propanediol, 1,4-butanediol, succinic and adipic acids. Polymer 122:105-116

Fang MY, Jin LH, Zhang C, Tan YY, Jiang PX, Ge N, Li HP, Xing XH (2013) Rapid mutation of Spirulina platensis by a new mutagenesis system of atmospheric and room temperature plasmas (ARTP) and generation of a mutant library with diverse phenotypes. PLOS ONE 8(10):e77046

Feron VJ, Til HP, Vrijer FD, Woutersen RA, Cassee FR, Bladeren JV (1991) Aldehydes: occurrence, carcinogenic potential, mechanism of action and risk assessment. Mutat Res 259:363-385

Garg SK, Jain A (1995) Fermentative production of 2,3-butanediol: a review. Bioresour Technol 51(3):103-109

Hazeena SH, Pandey A, Binod P (2016) Evaluation of oil palm front hydrolysate as a novel substrate for 2,3-butanediol production using a novel isolate Enterobacter cloacae SG1. Renew Energy 98:216-220

Hua XF, Wang J, Wu ZJ, Zhang HX, Li HP, Xing XH, Liu Z (2010) A salt tolerant Enterobacter cloacae mutant for bioaugmentation of petroleum- and saltcontaminated soil. Biochem Eng J 49(2):201-206

Jiang LQ, Fang Z, Guo F, Yang LB (2012) Production of 2,3-butanediol from acid hydrolysates of Jatropha hulls with Klebsiella oxytoca. Bioresour Technol 107:405-410

Jiang M, Chen GS, Lu P, Jian Dong (2014) Preparation of aqueous soluble polyamides from renewable succinic acid and citric acid as a new approach to design bio-inspired polymers. J Appl Polym Sci. https://doi. org/10.1002/APP.39807

Joo J, Lee SJ, Yoo HY, Kim YH, Jang M, Lee J, Han SO, Kim SW, Park C (2016) Improved fermentation of lignocellulosic hydrolysates to 2,3-butanediol through investigation of effects of inhibitory compounds by Enterobacter aerogenes. Chem Eng J 306:916-924

Lee SJ, Lee JH, Yang X, Kim SB, Lee JH, Yoo HY, Park C, Kim SW (2015) Phenolic compounds: strong inhibitors derived from lignocellulosic hydrolysate for 2,3-butanediol production by Enterobacter aerogenes. Biotechnol J 10(12):1920-1928

Liu CG, Xue C, Lin YH, Feng WB (2013) Redox potential control and applications in microaerobic and anaerobic fermentations. Biotechnol Adv 31(2):257-265

Liu B, Sun Z, Ma X, Yang B, Jiang Y, Wei D, Chen F (2015) Mutation breeding of extracellular polysaccharide-producing microalga Crypthecodinium cohnii by a novel mutagenesis with atmospheric and room temperature plasma. Int J Mol Sci 16(6):8201-8212

Lloyd TA, Wyman CE (2005) Combined sugar yields for dilute sulfuric acid pretreatment of corn stover followed by enzymatic hydrolysis of the remaining solids. Bioresour Technol 96(18):1967-1977

Miller EN, Jarboe LR, Turner PC, Pharkya P, Yomano LP, York SW, Numm D, Shanmugam KT, Ingram LO (2009) Furfural inhibits growth by limiting sulfur assimilation in ethanologenic Escherichia coli strain LY180. Appl Environ Microbiol 75(19):6132-6141

Parawira W, Tekere M (2011) Biotechnological strategies to overcome inhibitors in lignocellulose hydrolysates for ethanol production: review. Crit Rev Biotechnol 31(1):20-31

Schirmer-Michel AC, Flores SH, Hertz PF, Ayub ZMA (2009) Effect of oxygen transfer rates on alcohols production by Candida guilliermondii cultivated on soybean hull hydrolysate. J Chem Technol Biotechnol 84(2):223-228

Tran AV, Chambers RP (1987) The dehydration of fermentative 2,3-butanediol into methyl ethyl ketone. Biotechnol Bioeng 29(3):343-351

Varga E, Klinke HB, Reczey K, Thomsen AB (2004) High solid simultaneous saccharification and fermentation of wet oxidized corn stover to ethanol. Biotechnol Bioeng 88(5):567-574

Wang XL, Li ZW, Chen LH, Liu XB, Xie HB (2007) The development of physical mutation techniques in industrial microbe breeding. Biotechnol Bull 2:114-118

Wang LY, Huang ZL, Li G, Zhao HX, Xing XH, Sun WT, Li HP, Gou ZX, Bao CY (2010) Novel mutation breeding method for Streptomyces avermitilis using an atmospheric pressure glow discharge plasma. J Appl Microbiol 108(3):851-858 
Wu J, Cheng KK, Li WY, Feng J, Zhang JA (2013a) Effect of acetic acid, furfural and 5-hydroxymethylfurfural on fermentation of 2,3-butanediol using Klebsiella oxytoca. Chin J Biotechnol 29(3):350-357

Wu J, Cheng KK, Wang GY, Li WY, Feng J, Zhang JA (2013b) Analysis of acetic acid, furfural and 5-hydroxymethylfurfural affecting 2,3-butanediol production using Klebsiella oxytoca. J Chem Technol Biotechnol 88(12):2239-2243

Wu J, Liu HJ, Yan X, Zhou YJ, Lin ZN, Cheng KK, Zhang JA (2018) Co-production of 2,3-BDO and succinic acid using xylose by Enterobacter cloacae. J Chem Technol Biotechnol 93:1462-1467

Zeng F, Tenn WJ, Aki SNVK, Xu JY, Liu B, Hohn KL (2016) Influence of basicity on 1,3-butadiene formation from catalytic 2,3-butanediol dehydration over gamma-alumina. J Catal 344:77-89
Zhang X, Wang L, Zhang C, Chen Y, Chang H, Li H, Xing X (2014a) Recent progress on atmospheric and room temperature plasma mutation breeding technology and its applications. Ciesc J 65:2676-2684

Zhang X, Zhang XF, Li HP, Wang LY, Zhang C, Xing XH, Bao CY (2014b)

Atmospheric and room temperature plasma (ARTP) as a new powerful mutagenesis tool. Appl Microbiol Biotechnol 98(12):5387-5396

\section{Publisher's Note}

Springer Nature remains neutral with regard to jurisdictional claims in published maps and institutional affiliations.

\section{Submit your manuscript to a SpringerOpen ${ }^{\circ}$ journal and benefit from:}

- Convenient online submission

- Rigorous peer review

- Open access: articles freely available online

- High visibility within the field

Retaining the copyright to your article

Submit your next manuscript at $\boldsymbol{\nabla}$ springeropen.com 